\title{
Adolescents' Internet Attitudes: A Study in an Experimental Greek Secondary School
}

\author{
Kleopatra Nikolopoulou \\ University of Athens, Greece \\ klnikolopoulou@ath. for thnet.gr
}

\begin{abstract}
This paper regards a validation study aiming to investigate secondary school pupils' internet attitudes. An 18-item questionnaire was administered to 260 adolescents (12-15 years old) of an experimental school, in Greece. Four factors were extracted: "affection", "perceived usefulness", "perceived control" and "behaviour". The factorial structure of the questionnaire was revealed. The majority of the pupils expressed strong perceptions towards the usefulness of the internet. Over $90 \%$ of the adolescents believe that the internet can allow them to do more interesting and imaginative work and that it helps them acquire relevant information. Gender and age were not significantly correlated to the factors. The frequency of internet use had positive correlations with the factor "Behaviour". "Perceived control" was statistically significant correlated with each of the factors "Affection" and "Perceived usefulness". The findings are discussed within the context of the safe introduction of digital tools ecosystems of this experimental school in Greece.
\end{abstract}

Keywords: Internet $\cdot$ Attitudes $\cdot$ Adolescents

\section{Introduction and Research Background}

In today's digital knowledge societies, internet literacy plays and will play an important role for all citizens to become information literate and lifelong learners. Today, pupils grow up in an environment where information technology and computers are used intensively. Adolescents have become one of the major groups using the internet for various purposes such as searching for information, communicating or playing games. In parallel, learners' perceptions and attitudes of the internet have been identified as important factors that affect learners' motivation, interest and performance in internet-based learning environments [1]. According to researchers [2], students' internet attitudes should be regarded as a component of internet literacy. Most of today's pupils are very comfortable with digital technology, while "digital citizenship" (the norms of behaviour with regard to technology use) regards several levels of responsibility for technology [3]. For example, pupils practise responsible use of technology and develop positive attitudes toward technology applications that support lifelong learning, collaboration and productivity. In the twenty-first century, citizens' attitudes toward using and learning the internet may determine the educational and economical development of a society. Students' internet attitudes may impact their future involvement in internet-related careers or activities. 
Assessing students' internet attitudes with validity and reliability is necessary for future internet related research. Tsai's et al. study [4] developed an internet attitude scale for high school pupils and identified the following four subscales: "perceived usefulness", "affection", "perceived control”, and "behaviour". Perceived usefulness regards pupils' perceptions about the positive impacts of the internet on individuals and society, affection regards pupils' feeling and anxiety when using the internet, perceived control regards pupils' confidence about the independent control of the usage of the internet, and behaviour regards pupils' actual practice and frequency of using the internet.

Tsai \& Lin [5] used the above mentioned scale in order to investigate Taiwanese adolescents' attitudes regarding the internet. They found that males expressed significantly more positive attitudes than did females on two aspects of the internet: perceived usefulness and perceived control. No significant gender differences were found in terms of the affection and behaviour aspects of using the internet. Tsai \& Tsai [6] reported lack of significant gender differences in adolescents' frequency of internet usage.

This paper is a validation study aiming to investigate secondary school pupils' internet attitudes, in an experimental school in Greece. Investigating adolescents' attitudes regarding the internet is important as these are expected to influence their intentions, their practices (e.g., internet usage) and, in turn, their learning.

\section{Objectives of the study}

The research objectives were:

1. To reveal the factorial structure of the internet attitude scale/ questionnaire (see [4]) and the relationships among factors regarding pupils' internet attitudes.

2. To investigate the impact of pupils' individual characteristics (gender, age, frequency of internet use) on the "internet attitudes" factors.

\section{Methodology}

\subsection{Context of the Experimental School and Sample}

Before describing the sample, the context for the operation of experimental schools in Greece is briefly presented. According to the Greek Official Government newspaper [7], in experimental schools are tried new programmes of studies, new teaching tools, new textbooks and other educational materials, new teaching methods and ways of managing the school unit. Such pilot applications and methods are being designed by the Greek Ministry of Education, by Universities, as well as by DEPPS (education consultants) or by the same school units, with the aim to create fruitful conclusions with regard to the improvement of educational policy. Teachers working in experimental schools have increased qualifications (i.e., they hold postgraduate degrees and a PhD degree) so as to be able to conduct and evaluate new pilot methods, and to provide feedback for the improvement of the educational policy in Greek schools. Experimental schools are also linked to Universities and, as a consequence, these are the schools where University students carry out their teaching 
practice. Additionally, for the development of talents and inclinations of pupils, clubs are created and operate across the curriculum once or twice a week (approved by DEPPS): clubs relate to cognitive domains such as mathematics, science, language, literature and other fields such as art, sports, etc., in order to create nuclei of creativity and excellence that utilize the increased capacity of some pupils. Within the above described context, teachers and individual experimental schools are relatively autonomous (under the approval of DEPPS) in the way they organise the school's curriculum. Thus, any innovative practices (including ICT/ digital practices) could come under the innovative educational practices. Teachers can also take initiatives such as to conduct research studies; their findings are expected to be useful for the educational community. The current study was undertaken after a teacher's initiative.

The sample consisted of 260 adolescent pupils of an experimental secondary/ high school in Piraeus, in Greece. Demographic and individual characteristics of the sample (grade and age group, gender, frequency of internet use) are shown in Table 1. All pupils have access to a computer at home. The age of pupils ranged from 12 to 15 years old. Regarding frequency of internet usage, $53.8 \%$ of the pupils reported they make internet use "daily", while around $26.5 \%$ use the internet "2-4 times per week". There were no gender differences regarding the frequency of internet use. The questionnaire was administered at the beginning of the academic year 2016-2017. The responses were anonymous and the pupils were assured that there was not right or wrong answer.

Table 1. Demographic and individual characteristics of the sample (260 pupils)

\begin{tabular}{ll}
\hline \multicolumn{1}{c}{ Age group } & Gender \\
\hline $12-13$ years old (or year 7) (38.1\%) & \\
$13-14$ years old (or year 8) $(36.5 \%)$ & Male (51.2\%) \\
$14-15$ years old (or year 9) $(25.4 \%)$ & \multicolumn{1}{c}{ Female (48.8\%) } \\
\hline \multicolumn{1}{c}{ Frequency of internet use at home } \\
\hline Less than once per month (6.2\%) \\
Monthly (2-4 times per month) $(13.5 \%)$ \\
Weekly (2-4 times per week) (26.5\%) \\
Every day (daily) (53.8\%)
\end{tabular}

\subsection{The Research Instrument}

Data were collected by the use of a questionnaire, which consisted of two sections. Section A involved statements regarding pupils' demographic and individual characteristics (gender, year of study, age, access to a computer at home, frequency of computer use at home). Section B involved 18 statements/ items aiming to investigate pupils' internet attitudes. All statements were taken from the study of Tsai et al. [4] who used the "Internet Attitudes Survey (IAS)" with Taiwan high school pupils. Their study separated the 18 items into four subscales/ factors, as follows: their first group/ factor involved five items (S14, S22, S26, S30, S32) related to "perceived usefulness", the second group/ factor involved five items/ statements (S5, S17, S21, S25, S29) related to "affection", the third group involved five items (S3, S15, S19, 
S23, S27) related to "perceived control", and the fourth group involved three items (S8, S16, S20) related to "behaviour". A detailed description of the four scales is presented below:

(1) Perceived usefulness subscale: measuring/ assessing pupils' perceptions about the positive impacts of the internet on individuals and society. A sample item of this scale is "the internet makes a great contribution to human life".

(2) Affection subscale: measuring pupils' feeling and anxiety when using the internet. A sample item of this scale is "the internet makes me feel uncomfortable".

(3) Perceived control subscale: investigating pupils' confidence about the independent control of the usage of the internet. A sample item of this scale is "I can use the internet independently, without the assistance of others".

(4) Behaviour subscale: assessing pupils' perceived actual practice and frequency of using the internet. A sample item of this scale is "I spend much time on using the internet”.

In Tsai's et al. study [4] the internal reliability indexes, alpha coefficients, were adequate for the first three subscales, $0.82,0.71$, and 0.68 , and for the entire scale, 0.81 . Alpha was relatively low (0.49) only for the fourth scale, regarding internet use behaviour.

In the questionnaire, the 18 items were presented in mixed order, and the pupils were asked to rate their beliefs on a 4-point Likert-type scale ( 1 = strongly disagree, 2 = disagree, 3 = agree, 4 = strongly agree). Seven items, S5, S17, S21, S25, S29, S15 and S8 were reversed from negative to positive wording.

\subsection{Data analysis}

The statistical software SPSS version 20.0 (2011) was used for managing the data and conducting the statistical analyses (descriptive statistics, factor analysis, correlation analysis). Monte Carlo PCA for Parallel analysis [8] was used to conduct Parallel analysis.

\section{Results}

\subsection{Descriptive measures for pupils' views and factorial structure of the questionnaire}

To explore pupils' internet attitudes, a descriptive analysis was performed. Table 2 shows pupils' response rates (\%) on the 18 items of the questionnaire ( $\mathrm{n}=260$ pupils). The last column of the Table has added together the percentages of those who "agree" and "strongly agree". The majority of the pupils expressed strong perceptions regarding the usefulness of the internet. Indicatively, over $90 \%$ of the sample, believe that "the internet can allow me to do more interesting and imaginative work" (for S14: 93.1\%), that "the internet helps me acquire relevant information I need" (for S30: $91.2 \%$ ), while around $80 \%$ perceive as positive the impact of internet on individuals and society (items S26 and S32). 
Table 2. Pupils' response rates $(\%)$ on the 18 items of the questionnaire ( $n=260$ pupils)

\begin{tabular}{|c|c|c|c|c|c|}
\hline & $\begin{array}{l}\text { strongly } \\
\text { disagree }\end{array}$ & disagre & agree & $\begin{array}{l}\text { strongly } \\
\text { agree }\end{array}$ & $\begin{array}{l}\text { agree \& } \\
\text { strongly } \\
\text { agree }\end{array}$ \\
\hline $\begin{array}{l}\text { S14. The internet can allow me to do more } \\
\text { interesting and imaginative work }\end{array}$ & 3.5 & 3.5 & 33.5 & 59.6 & 93.1 \\
\hline $\begin{array}{l}\text { S30. The internet helps me acquire relevant } \\
\text { information I need }\end{array}$ & 4.6 & 4.2 & 37.7 & 53.5 & 91.2 \\
\hline $\begin{array}{l}\text { S26. The internet makes a great contribution to } \\
\text { human life }\end{array}$ & 5 & 14.2 & 40.8 & 40 & 80.8 \\
\hline S32. The internet makes society more advanced & 7.3 & 11.9 & 44.2 & 36.5 & 80.7 \\
\hline $\begin{array}{l}\text { S27. I can use the internet independently, without } \\
\text { the assistance of others }\end{array}$ & 6.2 & 15.4 & 33.5 & 45 & 78.5 \\
\hline S20. I spend much time on using the internet & 8.1 & 14.6 & 38.1 & 39.2 & 77.3 \\
\hline $\begin{array}{l}\text { S19. If I get problems using the internet, I can } \\
\text { usually solve them one way or the other }\end{array}$ & 6.9 & 15.8 & 48.8 & 28.5 & 77.3 \\
\hline $\begin{array}{l}\text { S3. I could probably teach myself most of the } \\
\text { things I need to know about the internet }\end{array}$ & 7.7 & 18.8 & 40 & 33.5 & 73.5 \\
\hline S22. The internet enlarges my scope & 5 & 21.5 & 45.8 & 27.7 & 73.5 \\
\hline S8. I only use the internet at school when told to $\wedge$ & 13.1 & 16.5 & 39.2 & 31.2 & 70.4 \\
\hline $\begin{array}{l}\text { S23. I do not need someone to tell me the best way } \\
\text { to use the internet }\end{array}$ & 9.6 & 23.5 & 30.8 & 36.2 & 67.0 \\
\hline S16. I use the internet regularly throughout school & 19.2 & 33.8 & 28.8 & 18.1 & 46.9 \\
\hline $\begin{array}{l}\text { S15. I need an experienced person nearby when I } \\
\text { use the internet } \wedge\end{array}$ & 39.6 & 31.9 & 19.6 & 8.8 & 28.4 \\
\hline $\begin{array}{l}\text { S29. When using the internet, I am not quite } \\
\text { confident about what I am doing } \wedge\end{array}$ & 46.9 & 28.8 & 15 & 9.2 & 24.2 \\
\hline S25. I feel bored toward using the internet $\wedge$ & 51.9 & 28.8 & 11.5 & 7.7 & 19.2 \\
\hline $\begin{array}{l}\text { S17. If given the opportunity to use the internet I am } \\
\text { afraid that I might damage it in some way } \wedge\end{array}$ & 57.3 & 24.2 & 10.4 & 8.1 & 18.5 \\
\hline $\begin{array}{l}\text { S5. I hesitate to use the internet in case } 1 \text { look } \\
\text { stupid } \wedge\end{array}$ & 64.2 & 18.8 & 10.4 & 6.5 & 16.9 \\
\hline S21. The internet makes me feel uncomfortable $\wedge$ & 61.2 & 25 & 8.8 & 5 & 13.8 \\
\hline
\end{tabular}

An exploratory factor analysis was performed, using Principal Axis Factoring method accompanied by the Oblimin Factor rotation method, in order to investigate the factorial validity of the 18 item questionnaire. KMO coefficient of sampling adequacy, 0.804 , was satisfactory (data eigenvalues $4.25,2.87,1.46$ and 1.34). The screen plot and the parallel analysis results support a four factor solution which was retained for interpretation. The first factor (F1) was labelled "Affection", the second factor (F2) was labelled "Perceived usefulness", the third factor (F3) was labelled "Perceived control" and the fourth factor (F4) was labelled "Behaviour". Table 3 displays the loadings and the Chronbach-a coefficient for internal consistency for each factor (F1 to F4). The first three factors show an acceptable internal consistency: Chronbach-a coefficient ranged from 0.661 to 0.847 . Loadings with an absolute value greater than 0.5 appear in Table 3. The fourth factor labelled "Behaviour" was loaded by three items and had low reliability (Chronbach-a $=0.332$ ). The "Perceived control" factor was statistically significant correlated with each of the factors "Affection" and 
"Perceived usefulness". Correlations were positive, as expected; small to mediocre significant correlation coefficients among factors $(\mathrm{p}<0.05)$ were found (Table 4$)$.

Table 3. Factor loadings per item (18 items)

\begin{tabular}{|c|c|c|c|c|}
\hline & \multicolumn{4}{|c|}{ Factors } \\
\hline & F1 & F2 & F3 & F4 \\
\hline S21. The internet makes me feel uncomfortable & .817 & & & \\
\hline $\begin{array}{l}\text { S17. If given the opportunity to use the internet I am } \\
\text { afraid that I might damage it in some way }\end{array}$ & .815 & & & \\
\hline S5. I hesitate to use the internet in case I look stupid & .779 & & & \\
\hline S25. I feel bored toward using the internet & .731 & & & \\
\hline $\begin{array}{l}\text { S29. When using the internet, I am not quite confident } \\
\text { about what I am doing }\end{array}$ & .697 & & & \\
\hline $\begin{array}{l}\text { S15. I need an experienced person nearby when I use } \\
\text { the internet }\end{array}$ & .601 & & & \\
\hline $\begin{array}{l}\text { S26. The internet makes a great contribution to human } \\
\text { life }\end{array}$ & & .805 & & \\
\hline S22. The internet enlarges my scope & & .733 & & \\
\hline $\begin{array}{l}\text { S30. The internet helps me acquire relevant } \\
\text { information I need }\end{array}$ & & .723 & & \\
\hline S32. The internet makes society more advanced & & 697 & & \\
\hline $\begin{array}{l}\text { S14. The internet can allow me to do more interesting } \\
\text { and imaginative work }\end{array}$ & & .539 & & \\
\hline $\begin{array}{l}\text { S19. If I get problems using the internet, I can usually } \\
\text { solve them one way or the other }\end{array}$ & & & 695 & \\
\hline $\begin{array}{l}\text { S27. I can use the internet independently, without the } \\
\text { assistance of others }\end{array}$ & & & 669 & \\
\hline $\begin{array}{l}\text { S23. I do not need someone to tell me the best way to } \\
\text { use the internet }\end{array}$ & & & 639 & \\
\hline $\begin{array}{l}\text { S3. I could probably teach myself most of the things } \\
\text { I need to know about the internet }\end{array}$ & & & 627 & \\
\hline S8. I only use the internet at schools when told to & & & & .716 \\
\hline S16. I use the internet regularly throughout school & & & & .528 \\
\hline S20. I spend much time on using the internet & & & & .525 \\
\hline Cronbach-a & 0.847 & 0.761 & 0.661 & 0.332 \\
\hline
\end{tabular}

All responses ranged from 1 (strongly disagree) to 4 (strongly agree).

Factor 1 (F1): “Affection”, Factor 2 (F2): "Perceived usefulness”, Factor 3 (F3): "Perceived control”, Factor 4 (F4): "Behaviour”.

Extraction Method: Extraction Method: Principal Component Analysis. Rotation Method: Oblimin with Kaiser Normalization (a. Rotation converged in 8 iterations) 
Table 4. Correlations among internet attitudes factors and the frequency of internet use

\begin{tabular}{|c|c|c|c|c|}
\hline & $\begin{array}{l}\text { Frequency of } \\
\text { internet use }\end{array}$ & Affection & $\begin{array}{l}\text { Perceived } \\
\text { usefulness }\end{array}$ & $\begin{array}{l}\text { Perceived } \\
\text { control }\end{array}$ \\
\hline Affection & .024 & & & \\
\hline $\begin{array}{l}\text { Perceived } \\
\text { usefulness }\end{array}$ & .097 & .084 & & \\
\hline Perceived control & .066 & $.151^{*}$ & $.274^{* *}$ & \\
\hline Behavior & $.286^{* *}$ & -.023 & .061 & .057 \\
\hline
\end{tabular}

\subsection{Impact of pupils' individual characteristics (gender, age, frequency of internet use) on the "internet attitudes" factors}

In order to investigate the impact of specific individual characteristics (gender, age, frequency of internet use) on the "internet attitudes" factors extracted above (F1, F2, F3 and F4), an estimation of correlation coefficients was conducted (see Table 4). Table 4 displays the correlations among internet attitude factors and the frequency of internet use.

Positive correlations were found only between the frequency of internet use and the factor "Behaviour". A series of two-way analyses of variances were performed, each of which had as dependent variable the factors (F1 to F4) expressed by factor scores produced from factor analysis, and as independent variables the gender and the grade (i.e., pupils' age group) (see Table 5). There was no interaction effect between gender and grade. Additionally, no statistical significant correlations were found among pupils' grade (or age-group), gender and the factors (Table 5).

Table 5. "Internet attitudes” factor scores by gender and grade

\begin{tabular}{|c|c|c|c|c|c|c|c|c|c|c|}
\hline & \multicolumn{6}{|c|}{ grade (age group) } & \multicolumn{4}{|c|}{ gender } \\
\hline & \multicolumn{2}{|c|}{$12-13$} & \multicolumn{2}{|c|}{$13-14$} & \multicolumn{2}{|c|}{$14-15$} & \multicolumn{2}{|c|}{ Boy } & \multicolumn{2}{|c|}{ Girl } \\
\hline & Mean & S.D. & Mean & S.D. & Mean & S.D. & Mean & S.D. & Mean & S.D. \\
\hline Affection & .045 & .839 & .001 & 1.072 & -.068 & 1.120 & -.066 & 1.047 & .069 & .947 \\
\hline $\begin{array}{l}\text { Perceived } \\
\text { usefulness }\end{array}$ & -.020 & .906 & .073 & 1.039 & -.076 & 1.083 & .066 & 1.050 & -.069 & .944 \\
\hline $\begin{array}{l}\text { Perceived } \\
\text { control }\end{array}$ & .069 & .909 & -.069 & 1.012 & -.004 & 1.115 & -.015 & 1.067 & .016 & .928 \\
\hline Behaviour & -.365 & .966 & .300 & 1.013 & .115 & .863 & .016 & .995 & -.017 & 1.008 \\
\hline
\end{tabular}

Note: Values in the same row and sub-table not sharing the same subscript are significantly different at $\mathrm{p}<.05$ in the two-sided test of equality for column means. Cells with no subscript are not included in the test. Tests assume equal variances ${ }^{1}$.

1 Tests are adjusted for all pairwise comparisons within a row of each innermost sub-table using the Bonferroni correction. 


\section{Discussion and Conclusions}

This was a validation study aiming to investigate secondary school pupils' internet attitudes, in an experimental school in Greece. This study adds to the body of empirical evidence regarding adolescents' internet attitudes. Investigating adolescents' internet attitudes is important as these are expected to influence their motivation and their practices. These, in turn, may impact on their learning.

With regard to the first objective (to reveal the factorial structure of the internet attitude scale/ questionnaire and the relationships among factors regarding pupils' views), the analysis demonstrated that there were four factors in the 18-item questionnaire: "Affection” (Factor 1 or F1), "Perceived usefulness” (Factor 2 or F2), "Perceived control” (Factor 3 or F3) and "Behaviour" (Factor 4 or F4) (Table 3). This reveals the factorial structure of the questionnaire and indicates that literatureoriginated constructs of "internet attitudes" do not differ between adolescent populations of different countries (e.g., adolescents in Taiwan and in Greece). There was a very strong agreement with the factors proposed by Tsai et al. [4] - whose scale was used in this study. In particular, all factors included (were consisted of) the same identical items, with the exception of one item (S15: I need an experienced person nearby when I use the internet); this item, in Tsai's et al. study was included in the subscale/ factor "perceived control", while in this study it loaded on the subscale "affection". As revealed in this study and as suggested by Tsai et al. [4], the factors "affection", "perceived usefulness" and "perceived control” should be distinct, when investigating pupils' attitudes towards the internet. The descriptive analysis revealed that there is a similarity of pupils' views-perceptions across cultures. Regarding pupils' views, the majority of them expressed strong perceptions towards the usefulness of the internet. Over $90 \%$ of the adolescents believe that the internet can allow them to do more interesting and imaginative work and that it helps them acquire relevant information they need. This finding can be linked to the context of the experimental school, which encourages innovative practices (e.g., integration of digital tools). Pupils' positive attitudes towards the internet may constitute a starting point to motivate them to carry out school work that integrates safely the internet. Regarding digital safety/ security, Ribble [3] discussed nine areas of "digital citizenship" and provided strategies for teachers to employ and teach appropriate inschool behaviour: in the area 'education', a suggested strategy is to encourage pupils to come up with new and alternative uses of the internet and digital technologies.

With regard to the second objective, to investigate the impact of pupils' individual characteristics (gender, age, frequency of internet use) on the internet attitudes factors, it was found that: (a) there was no impact of pupils' grade (or age group) and gender on the internet attitudes factors, and (b) the frequency of internet use had positive correlations with the factor "Behaviour". Finding (a) above, is in some agreement with earlier studies which showed that gender differences were nonexistent. Tsai \& Lin [5] found that males expressed significantly more positive attitudes than did females on the subscales "perceived usefulness" and "perceived control", whereas no significant gender differences were found on the "affection" and "behaviour” subscales. Tsai \& Tsai [6] reported lack of significant gender differences in adolescents' frequency of internet usage. Since the traditional gender gap in elementary and secondary school pupils seems to be narrowing ([9], [6]), it is 
suggested for gender differences to be investigated with regard to particular aspects of the internet, and also across generations. The finding that there was no impact of pupils' grade (or age group) on the internet attitudes factors was probably due to the small range of ages (i.e., 12 to 15 years old). Finding (b) above, was expected as the frequency of internet use is linked to the items of the factor "Behaviour" (e.g., items S16: "I use the internet regularly throughout school" and S20: "I spend much time on using the internet”). The fact that the frequency of internet use was not significant correlated to the other factors, makes stronger the argument/ suggestion that the scales-factors "affection”, "perceived usefulness" and "perceived control” should be distinct (discrete) when defining concepts related to internet views.

Limitations of this study include the narrow age-range of pupils and the lack of investigating other internet related variables (e.g., pupils' internet self-efficacy). In this study, the reliability coefficients (Cronbach's alpha) were adequate for the first three subscales (F1, F2 and F3 had 0.847, 0.761 and 0.661 , respectively). This suggests that these internet attitude scales, which were developed by Tsai's et al. [4], are a reliable tool to investigate adolescents' internet attitudes across different countries and cultures (it allows for establishment of comparability with studies in different cultures). Since attitudes towards the internet are a multidimensional factor, it is considered as appropriate to describe adolescents' attitudes with respect to discrete dimensions (factors), such as those revealed by the questionnaire. It is suggested, this scale to be used with different adolescent and other target populations (e.g., young University students), in other countries, in order to reveal possible similarities and differences. New internet applications with new features, which cannot easily be foreseen, will appear in the future. Because of the rapidly changing digital technology, adolescents' internet attitudes need to be defined and measured throughout the time.

This small scale study was carried out in an experimental school in Greece. The policy of this school encourages teachers to undertake research initiatives, to disseminate the findings and to participate in the (self)-evaluation of the school unit. The findings of this study are expected to have implications for this school's “ecosystem". According to Davis [10], information technology impacts multiple ecologies and it is also impacted by these ecologies. It is suggested for teachers to follow short in-service courses (e.g., organized by the information technology teacher-specialist) to be informed about safe internet uses under the umbrella of “digital citizenship" (this concept was defined and discussed by Ribble [3]). Teachers of various subjects need to be aware of pupils' positive views towards the internet, so as to motivate them to carry out innovative work within a safe environment. In this way, teachers' and pupils' practices may influence the school's context. Further research is planned to be conducted in this experimental school. It is suggested to investigate the relation between pupils' internet attitudes and their learning achievements. By adopting a robust methodology, the teacher-researcher (author of this paper) plans to investigate (a) appropriate and inappropriate uses of mobile technology by pupils, and (b) the ecosystem of this school with regard to information technology (e.g., teachers' technology use and practices in various subjects, as well as their perspectives). 
Acknowledgments. The author would like to thank Prof. N. Davis for her suggestions on this paper

\section{References}

1. Peng, H., Tsai, C.-C, Wu, Y.-T.: University students' self-efficacy and their attitudes toward the internet: the role of students' perceptions of the internet. Educational Studies, 32, 73-86 (2006)

2. Wu, Y.-T., Tsai, C.-C.: University students' internet attitudes and internet self-efficacy: A study at three Universities in Taiwan. Cyber Psychology \& Behavior, 9(4), 441-450 (2006)

3. Ribble, M.: Digital citizenship in schools. Second edition, ISTE (International Society for Technology in Education): $2^{\text {nd }}$ chapter, pp. 15-44, https://www.iste.org/docs/excerpts/DIGCI2-excerpt.pdf (2011)

4. Tsai, C.-C., Lin, S., Tsai, M.-J.: Developing an internet Attitude Scale for high school students. Computers \& Education, 37, 41-51 (2001)

5. Tsai, C.-C., Lin, C.-C.: Taiwanese adolescents' perceptions and attitudes regarding the internet: Exploring gender differences. Adolescence, 39(156), 725-734 (2004)

6. Tsai, M.-J., Tsai, C.-C.: Junior high school students' internet usage and self-efficacy: A re-examination of the gender gap. Computers \& Education, 54, 1182-1192 (2010)

7. Official Greek Government newspaper: Context for experimental schools (in Greek), (2011, modified in 2015)

8. Watkins, M. W.: Monte Carlo PCA for Parallel Analysis (computer software). State College, PA: Ed \& Psych Associates (2000)

9. Volman, M., van Eck, E., Heemskerk, I., Kuiper, E.: New technologies, new differences: Gender and ethnic differences in pupils' use of ICT in primary and secondary education. Computers \& Education, 44(1), 35-55 (2005)

10. Davis, N.: Global interdisciplinary research into the diffusion of information technology innovations in education. In McDougall, A., Murnane, J., Jones A., Reynolds N. (eds.) Researching IT in Education: Theory, Practice and Future Directions, pp. 142-149. Routledge, London (2010) 